\title{
PHOTO SCANNER 3D SURVEY FOR MONITORING HISTORICAL MONUMENTS. THE CASE HISTORY OF PORTA PRAETORIA IN AOSTA
}

\author{
Paolo SALONIA ${ }^{1}$, Tommaso LETI MESSINA ${ }^{1}$, \\ Andrea MARCOLONGO ${ }^{1}$, Lorenzo APPOLONIA ${ }^{\circ}$
}

\author{
${ }^{1}$ CNR, Institute for Technologies Applied to Cultural Heritage, Rome Research \\ Area, Via Salaria, km 29.300, 00016 Monterotondo St. (Rome) ITALY \\ paolo.salonia@itabc.cnr.it, tommaso.letimessina@itabc.cnr.it, a.marcolongo@arch3.eu \\ ${ }^{\circ}$ Direzione ricerca e progetti cofinanziati - Dipartimento soprintendenza per i beni e \\ le attività culturali - Assessorato istruzione e cultura - Regione Autonoma Valle d'Aosta \\ paolo.salonia@itabc.cnr.it, tommaso.letimessina@itabc.cnr.it, a.marcolongo@arch3.eu
}

\begin{abstract}
Keywords: Terrestrial Photo Scanner 3D, UAV, Image processing, Points clouds RGB, Multiscale, GIS Monitoring Cultural Heritage.
\end{abstract}

\begin{abstract}
Accessibility to cultural heritage is one of the most important factors in cultural heritage preservation, as it assures knowledge, monitoring, Public Administration management and a wide interest on cultural heritage sites. Nowdays 3D surveys give the geometric basis for an effective artefact reconstruction but most of the times 3D data are not completely and deeply investigated to extract other useful information on historical monuments for their conservation and safeguard. The Cultural Heritage Superintendence of Aosta decided to run a time continual project of monitoring of the Praetorian Roman Gate with the collaboration of the ITABC, CNR of Italy. The Praetorian Roman Gate in Aosta, Italy, of Augustus ages, is one of the most well-known roman monumental gates, it is a double gate with three arches each side, 12 meters high, 20 meters wide, made of pudding stone ashlars, Badoglio, travertine, marble blocks and other stone insertion due to restorations between 1600 and 1950. In years 2000 a final restoration intervention brought the gate at the present state of art, within the frame of a restoration and conservation building site with the purpose of treat the different decay pathologies and conditions. A complete 3D geometric survey campaign has been the first step for the monitoring of the gate morphologic changes and decay progress in time. The main purpose is to collect both quantitative data, related to the geometry of the gate, and the qualitative data, related to the chromatic change on the surface due to the stone decay. The geometric data with colour information permits to associate materials and stone pathologies to chemical or mechanical actions and to understand and analyse superficial decay kinetics. The colours survey will also permit to directly locate on the 3D model areas of different stratigraphic units. The project aims to build a rigorous quantitative-qualitative database so to be uploaded into a GIS. The GIS will become the monitoring main means. Considering the huge dimension of the gate and its urban location a multi-scale approach has been considered. Controlled and free images have been taken from the ground and the top of the gate so to reconstruct all the walls and the upper cover. A topographic survey has been done so to be able to control and relate all the different acquisitions. It has been chosen a Photo Scanner 3D system. It is a photogrammetry-based survey technology for point clouds acquisition and 3D models configuration, from digital images processing. This technology allows to obtain point clouds (xyz coordinates) with RGB information and geometries at different levels of complexity by processing a number of images taken with a limited set of constraints, with the use of a simple acquisition equipment and through an image matching algorithm (ZScan, by Menci Software). Due to the high walls of the arch gates, the higher part has been surveyed with a remote controlled drone (UAV Unmanned Aerial Vehicle) with a digital camera on it, so to take pictures up to the maximum altitude and with different shooting angles ( 90 and 45 degree). This is a new technology which permits to survey inaccessible parts of a high monument with ease and accuracy, by collecting redundant pictures later bound together by an image block algorithm. This paper aims to present the survey experience architectural monuments trough the application of a trifocal quick photogrammetric system, in surveying at different scales and for different purposes.
\end{abstract}

\section{THE PROJECT}

\subsection{The case history monument}

“...One of the best monuments of the Roman military architecture is undoubtedly the Porta Pretoria d'Aosta, called Porta S. Urso, because of the near ancient church, and later named Gate of the Trinity from a chapel built in recent 
centuries. But the living traditions gives it, at least from the revival of letters on, the name of Porta Pretoria still the true appellation. (Carlo Promis, Le antichità di Aosta, Capo VII, \& 1. Porta Pretoria nello stato presente, Stamperia Reale, Torino, 1862, pagg. 142-156) [1]. The Praetoria Door, or even Praetorian Gate or Praetorians Doors, is the gateway to the east of the Roman town of Augusta Praetoria Salassorum (today Aosta). It dates to the founding of the city and is the largest among those that have reached us from the Roman world, and "may be compared to the Gate of Mars or Porta Nigra in Treviri, Rhenish Prussia..." (Carlo Promis, op. cit.).
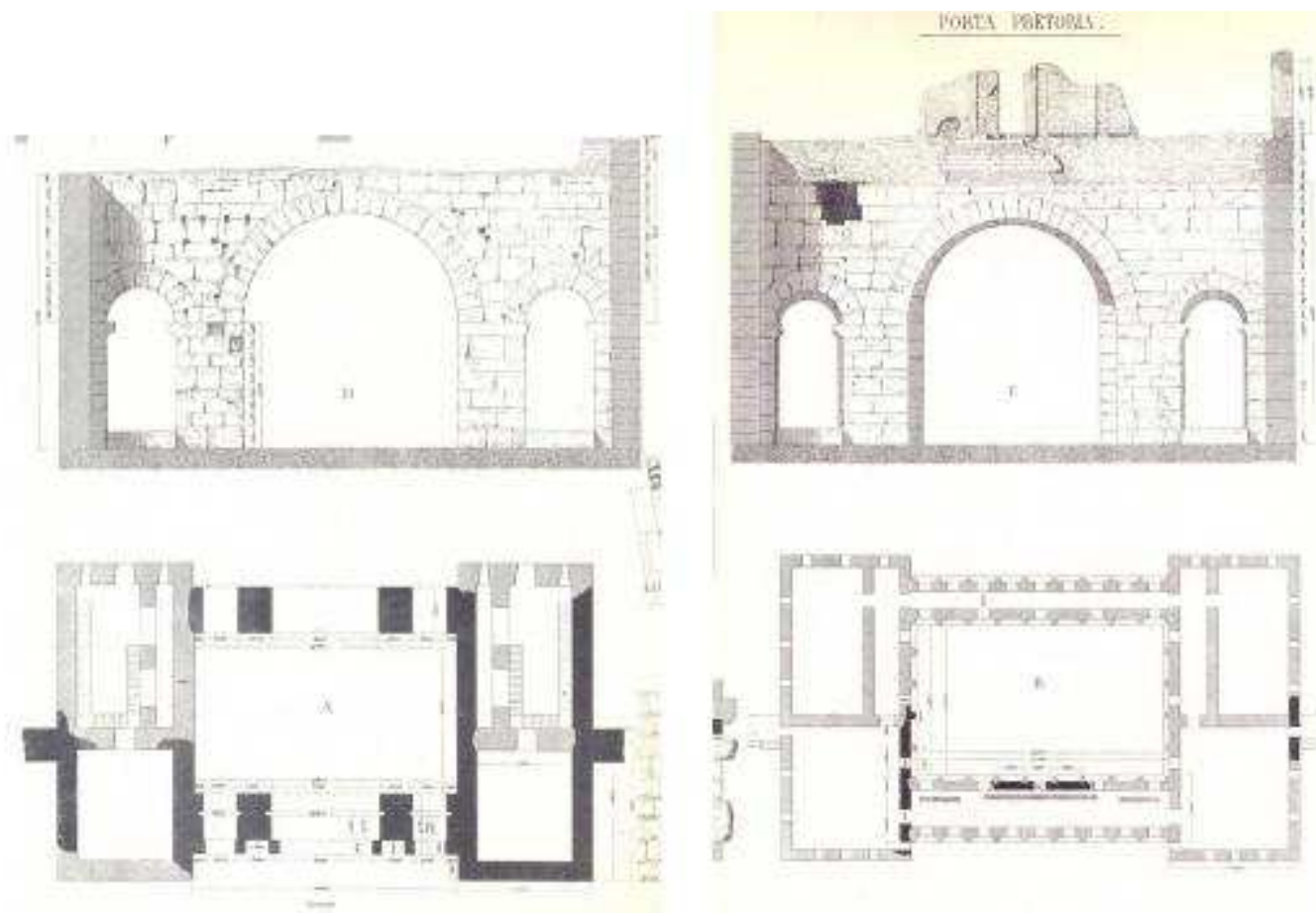

Figure 1: Praetorian Gate, plans and elevations in the reconstruction of Carlo Promis (Tav. V)

Built in $25 \mathrm{BC}$, is still in excellent condition and is formed by two defensive parallel walls of about $13 \mathrm{~m}$ high (compared to the street level), and in the lower part opened by three arches, the main central one and two smaller on the sides, separated by a parade ground of 12 meters. The external screen is 4.50 meters thick, while the interior has a thickness of 3.45 meters (Figure 1). On both edges are visible patrols, bounded by arched windows and defended by two towers. The central arch, which measures about 7 feet of light, it was intended for carriages to pass, while the two sides, 2.65 meters wide, for pedestrians. The three eastern lanes were closed with draw-gates, still visible in the housing. The two defensive towers have been reworked with a rectangular base over time, the northern most clearly, while the south still preserves some characteristics of Roman architecture. The door is constructed of large blocks of conglomerate (natural conglomerate) and the outer face of the eastern part is still covered in gray-green marble (bardiglio of Aymavilles), while the remains are of white marble carved with a frieze of the entablature, the cornice of 'Corinthian, leaves, ovules, corbels, cornices and arches. To get an idea of the enormous size of the door, one of the most beautiful buildings so well preserved, it must be remembered that the floor of the Roman city is at a level of about 2.60 meters below the existing roadbed. During the Middle Ages, the lords of Quart took possession of the door and of the two flanked towers to turn them into a fortified dwelling. Above the central eastern arch, at the ancient walkway, was built in the twelfth century a chapel dedicated to SS. Trinity. Until the eighteenth century a series of building obstructed the central and southern arches, and the only access to the city consisted of the northern passage: this explains why the road axis has moved, thus more oriented to the north. The restoration work carried out in the $30 \mathrm{~s}$ of last century, involved the demolition of the medieval buildings to the exclusion of the North Tower (Tower of the Lords) and the restoration of the southern regions now occupied by a restaurant. In December 2001, however, it was concluded the restoration of the stone parts of the monument. This intervention was necessary for the progressive deterioration caused by different environmental and climatic factors of stone masonry consisting mostly of conglomerate rock. During the execution of the various phases new elements have emerged that have helped to understand the construction phases of the monument itself.

\subsection{Methodological approach of the Project}

Within the vast project of analysis of the condition, diagnosis, planning and organization of a rigorous monitoring, consistent with the "conceptual route" started long ago with the Superintendency of Cultural and Environmental 
Heritage of the Region of Valle d'Aosta within the frame of other joint projects (see for example the relief of the city of Aosta urbica, the finding of early medieval frescoes of the Collegiate Church of Saint Orso in Aosta, the survey of the capitals in the cloister of the Collegiata and the Arch of Augustus ) [3, 4, 5, 6, 7, 8, 9], the Institute for Technologies Applied to Cultural Heritage (ITABC) of CNR in Rome has developed a rigorous 3D geometric documentation of the Praetorian Gate which is the basis on which then map all information on the conservation status of the monument. The ultimate aim of the project is to obtain, through the use of innovative techniques, an operational tool for the analysis of the building that, used by various technicians (archaeologists, architects, historians and restorers) in the survey phase, will became a valid support in the monitoring project management. This operational tool will configure then, first, as an instrument of research, for interactive questions on various topics (changes of degradation parameters for the component materials, colour, etc. .) so to extract necessary information to assess the state of preservation. It will also be a monitoring tool of significant parameters, so to be able to derive comparative assessments on used materials time behaviour, the kinetics of degradation and therefore the effectiveness of carried out interventions.

With reference to the foregoing, the three main objectives are:

- the creation of an accurate survey, detailed from both the geometric and the radiometric information, and a documentation package that, through the use of innovative methodologies and technologies, ensures added value of research and testing;

- $\quad$ setting up an operational tool for the analysis of the monument which brings together all the heterogeneous data that would complement the various actors in the learning phase, being a valuable support in monitoring and conservation;

- the transfer of know-how to the same administrative Authorities involved in the project by carrying out a phase of training on job designed to make them fully autonomous in the use of an operational tool also configured as a function of possible implementations and upgrades of documentation relating to the monument, with a view to its scheduled conservation.

With reference to the overall objectives of the project, aimed at the optimization and the easy management of information, coming from different disciplines it was possible to identify a specific operational path approach involving several distinct and defined phases.

These steps can be summarized as follows:

acquisition of data:

- geometric survey;

- visual analysis (types of degradation, building materials, etc.).

- non-invasive diagnostic tests;

- historical-critical analysis and documentary research.

integration and data management:

- development and optimization in a specific information system (ARKIS);

- identification of routes of investigation, interrogation and observation.

Of the different phases in which the project is articulated, this paper specifically wants to account the performed survey and the consistency of the acquired and processed data, and trace the lines of a future development.

\section{THE SURVEY}

\subsection{The geometrical survey: general criteria}

The three-dimensional survey of the Praetorian Gate, built according to innovative paradigms, so in this sense is completely non-existent at present, has been calibrated (in terms of detail, rendering, scale, etc..) on the same type of artefact to be investigated and, in relation with the primary purposes that the project intent arises, the used techniques have provided some essential traits such as reliability, accuracy and measurability of the returned data [2, 3, 4]. It also has three-dimensional requirements: the possibility of a stereo metric control of the monument is indeed very timely, given the important purpose of documentation. The obtained three-dimensional models, made available to the Administration, will be further elaborated in a later date, for the acquisition of a number of useful additional information so to increase knowledge for the conservation (relations between the different parts, alignments of the body wall, any misalignments, etc.) and then to plan additional surveys and analysis preliminary to the monitoring of the artefact and any simulations of restoration. Finally, allows the production of a detailed documentation, not only in terms of geometry (quantity) but also in terms of radiometry (qualitative), and therefore able to provide information on colour and morphology of the material components, and their possible alteration due to the widespread phenomena of degradation. In this regard, and in regard of the experimental and scientific connotation that we wanted to give to the whole survey, certain criteria have been identified, on which to base the design and implementation of documentation and relief operations. They can be summarized as follows:

use and testing of an innovative survey calibrated system, of triplets of images, which can produce accurate three-dimensional scans of the monument, through the production of point clouds with a complete space (xyz coordinates) and colorimetric (RGB values) information; 
- preliminary data acquisition, programming and planning post processing phases in accordance with special needs and/or any priorities. This ensures the Superintendent the possibility of creating a complete archive of heterogeneous basic documentation, permitting, at the same time, a different use of the funds available with obvious savings in time and cost;

ability to use the captured data (coordinates of points, point cloud, range maps, triplets of high-definition images, monographs, etc..) according to different methods in relation to specific and temporary needs of a technical nature (time and / or costs reduced by implementing a detailed analysis of more in-depth qualitative assessments of the state of consistency, etc..) or administrative (such as the choices that the Superintendent will decide whether or not to operate equipment on $\mathrm{HW}$ and $\mathrm{SW}$ ). These are basically two: monoscopic processing by orthogonal mosaics arising from the triplet of photographic images in order to obtain documentation, including paper documentation on which to perform a first level of analysis, being 2D drawings where the altitude ( $\mathrm{z}$ coordinate) is not considered and therefore, the information appears to be detectable only on the $\mathrm{x}$ to $\mathrm{y}$; 3D modeling from which to obtain digital surface models or three-dimensional environments the can be explored, suitable for the management of all processed data and useful information for study and analysis.

In both cases, this allows technicians to have a continuous information, characterized by the presence, on the exact "geometry " of the building, of all the qualitative data, with the possibility to add, to the precision of photogrammetric data, morphological qualitative data, related to colour and details of digital images and, therefore, to measure, calculate areas or create a decay thematic legend.

\subsection{The geometric survey: techniques and methodologies}

In terms of techniques and methodologies, the survey has been carried out through the use and testing of an innovative calibrated system of triplets of images, photo 3D scanner, capable of accurate 3D scans of detected objects, with the integration of geometric and colorimetric data without the use of laser scanner [5].

The used technology (ZScan, designed and produced by Menci Software Arezzo) [6] allows to obtain point clouds with RGB information from which to develop 3D models at different levels of complexity and scale, starting from the treatment of a discrete number of digital images, acquired in a controlled mode, by using specific equipment and postprocessing the data within a specific software based on an innovative algorithm for image matching. This is a survey system based on the achievement of redundant digital images of the monument made in known conditions: for each portion of the object are captured three different images from three different angles, following a simple set of procedures and through the use of an acquisition system and a photographic camera properly calibrated. The processing of each triplet of images, within a specific software environment which allows the application of a sophisticated algorithm for image processing, based on the principles of stereo-photogrammetry, allows the transformation of the individual pixels of images in a cloud of points of known coordinates, together with color information in RGB format, without the aid of any topographic support. From these point clouds can also be immediately obtained individual range maps, or triangulated mesh and texture of that surveyed individual portions of the object surface. The acquisition system then consists of a hardware, that is a camera with fixed optics appropriately calibrated (to know the value of the mounted lens distortion), a calibrated chassis of $90 \mathrm{~cm}$ mounted on a tripod with a rotating head and 3D software based on an algorithm of image analysis which makes it extremely efficient and precise. The digital camera can slide on the precision steel bar, where some holes have been prepared at known distances, which represent the possible positions of the camera itself. It consist basically to catch three shots in succession (left, centre, right) from different locations and with a considerable overlap between the individual shots (at least $30 \%$ ), with the foresight to define the interval between these positions in relation to distance of the object to be detected and the scale of the wanted detail. The survey system that offers, in conclusion, a number of benefits that can be summarized as follows:

- flexibility in the acquisition phase since, as been variable the distance between the sockets, it can be optimized depending on the size of the artefacts, the distance from the object and the actual conditions of recovery;

- $\quad$ speed in the acquisition phase with the ability to make cheaper topographic support (the pursuit of a high degree of accuracy should, however, be too stringent in that medium, using GCP (Ground Control Points);

- $\quad$ speed during the processing of data acquired for the presence of an appropriate software environment, associated with the system, which allows you to build three-dimensional models, whether in the form of clouds of points of triangular mesh by simply inserting images, and all of the triplet parameters related to recovery;

- ability to chain, in a development phase, the individual models obtained resulting in a total of three-dimensional object models, measurable, exploring and analyzing navigation in special environments [7, 8].

\subsection{Stages of survey and data processing}

In the specific case of the Praetorian Gate, a monument of particular complexity for its geometry and the global "urban" scale size, in order to be able to get both the entire roof of the building and the lower part, at present beneath the current street level, and to survey also the top and the intrados of the arches, as well as all the related artifacts, as the Tower of Lords, has been planned an intervention strategy that integrates different methods of acquisition. Specifically, we have 
surveyed with a huge amount of "controlled" triplets of images from the ground, "free" digital images, with a compact digital camera, positioned on a telescopic pole and images from drones or UAVs. The 3D photo scanner technology has, in fact, an extension application which allows a remote-controlled carrier (UAV Unmanned Aerial Vehicle) in order to perform aerial shots from different altitudes. Using this technology you can scan entire areas of each site with a significant perspective advantage (photo zenith) and obtain extremely accurate plano - altimetric reconstructions in terms of geometry and radiometry. Placing then the digital camera with an angle of 90 degrees it has been possible to survey the front facade and above the upper parts of the monument otherwise completely inaccessible, ensuring also a more reliable measure of those too foreshortened areas. An accurate topographic survey, both in elevation and plane to collect also a large number of GCP on the monument, which are necessary for the registration of individual point clouds into a single spatial reference system, has completed the stages of data acquisition. The integration between the different generated clouds of points has produced a complex three-dimensional model, at different levels of information density. In all, relief operations have required three days in the field, of which only half for the survey with the UAV system. The instrumentation used throughout the campaign has been:

- $\quad$ Pentax Total Station for the topographic survey

- $\quad$ Leica laser distance meters for direct measurement

- $\quad$ Nikon D-200 (10.2 megapixels CCD, 24mm lens, calibrated in a laboratory certified UNI) for the acquisition of point clouds with spatial information (xyz) and colorimetric (RGB)

- $\quad$ Canon S90 digital camera (10.2 megapixel CCD, calibrated in a laboratory certified UNI)

- $\quad$ Radio-controlled UAV esa-copter

- $\quad$ Aluminum bar ZScan calibrated system, mounted on a Manfrotto tripod

- $10 \mathrm{~m}$ telescopic pole

- Toshiba laptop for managing the acquisition and archiving of acquired data in real time.

During the first post processing phase, from each triplet has been obtained a three-dimensional model, both in the form of point clouds with an RGB value and of a triangle textured mesh, of each portion of the Gate. Similarly it was possible to produce 3D models in the form of point clouds from all the digital images acquired either "free" or with the UAV, by virtue of their high degree of overlap (no more than 50\%). These models were then registered each to the other, using data derived from the topographic support, to obtain an overall three-dimensional model, measured, analyzed and explored in a special navigation environment. Finally, from the three-dimensional model were obtained ortho-photos of the main facades which can be eventually vectorialized with CAD. This documentation was essential during the implementation of the use of ARKIS to handle all the monument information. The phase of data processing has been developed through the use of two software that are part of the ZScan system (ZScan ZMap and Laser). The first software allows the extraction, from every single sequence of triplets of images, of a single points cloud that contains spatial information and colorimetric coordinates XYZ and RGB. After checking the equalization of the color between each image, the three images, loaded the fundamental parameters (baseline and calibration files used in optics) are easily processed (Figure 2).

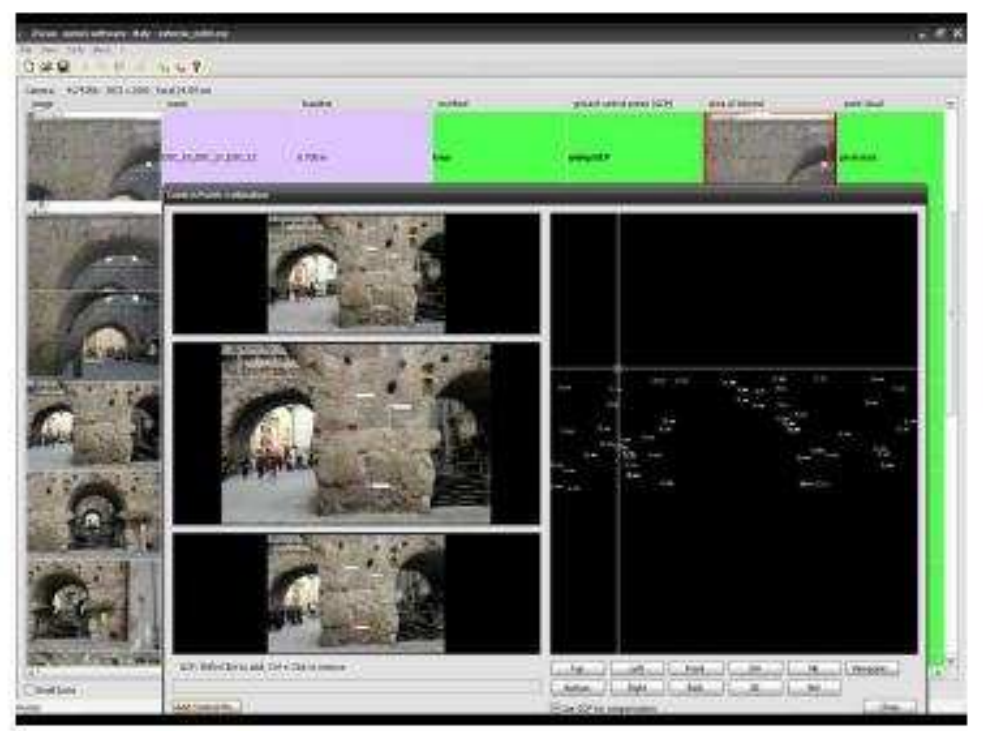

Figure 2: Computing environment Zscan 
The procedure at this point, consists of four basic steps:

- correction of the images through the application of a correction and trinocular matching feature, which makes the software automatically eliminate geometric distortions of lenses;

- $\quad$ selection of the image area of interest (AOI) to be processed

- determination of the desired resolution, measured in pixels;

- $\quad$ production of the cloud of points, one for each triplet, generated automatically thanks to an innovative image processing algorithms.

Simultaneously, the same software can also automatically create a triangulated and textured surface by a process of the point cloud triangulation.

In connection with the accuracy of the survey and of the wanted details, has been adopted as a resolution step a value of 3 pixels, which corresponds to $0.3 \mathrm{~mm}$ from point to point of the generated cloud. Each single point cloud has been registered with the near ones, and overlap cleaned, so to obtain a unique 3D model (Figure 3). The ZMap software allows two different types of recording: first, a semi automatic, which is based on the mutual recognition and collimation of significant homologous points between two different points clouds, secondly, a full automatic alignment, with the use of an image matching ICP algorithm. These procedures are used both for each model trying to compensate the propagation of errors throughout the process of orientation. The average accuracy obtained has been of $0.5 \mathrm{~mm}$.
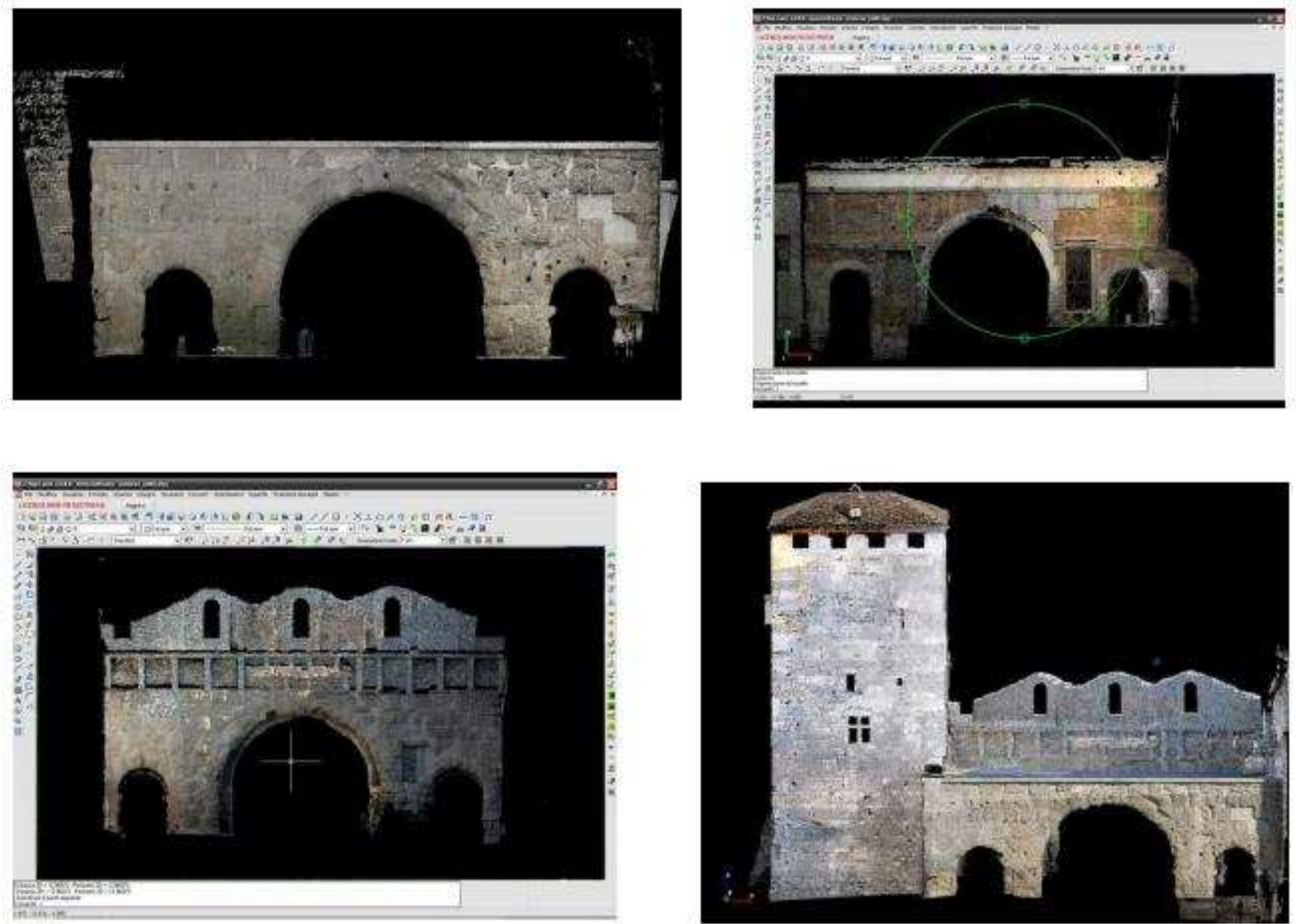

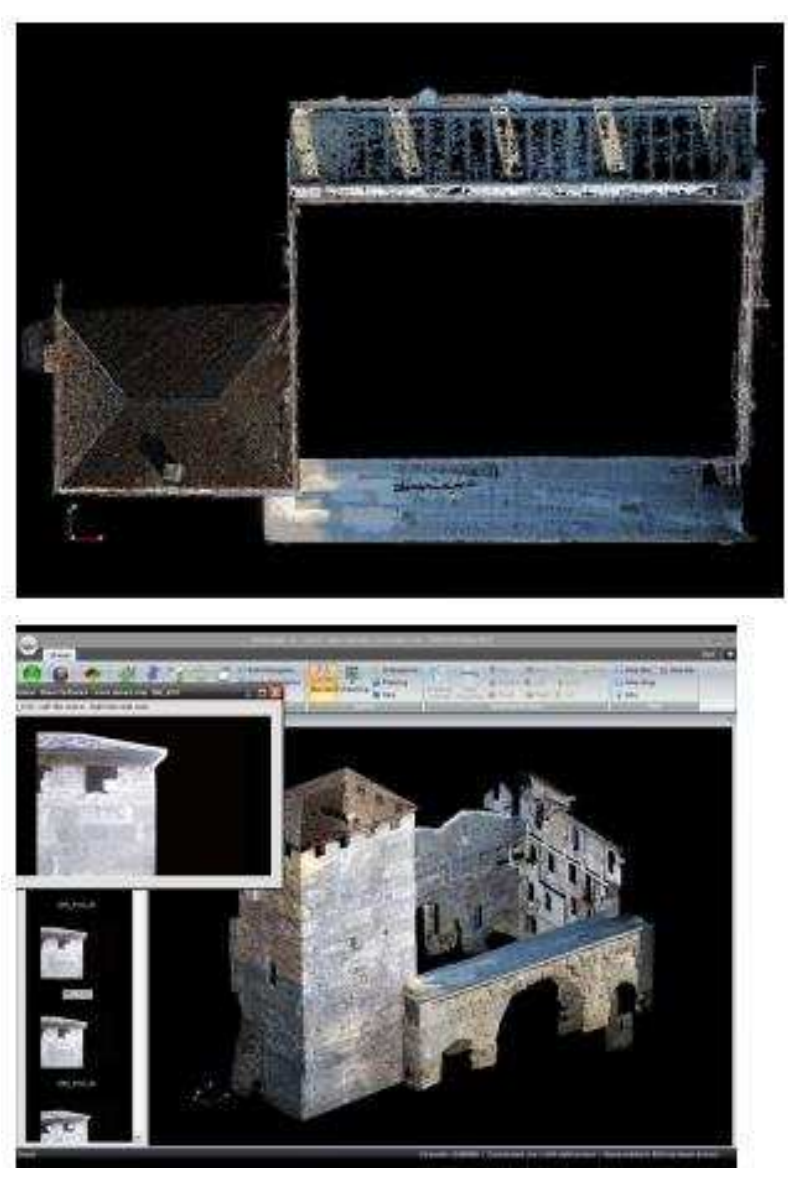
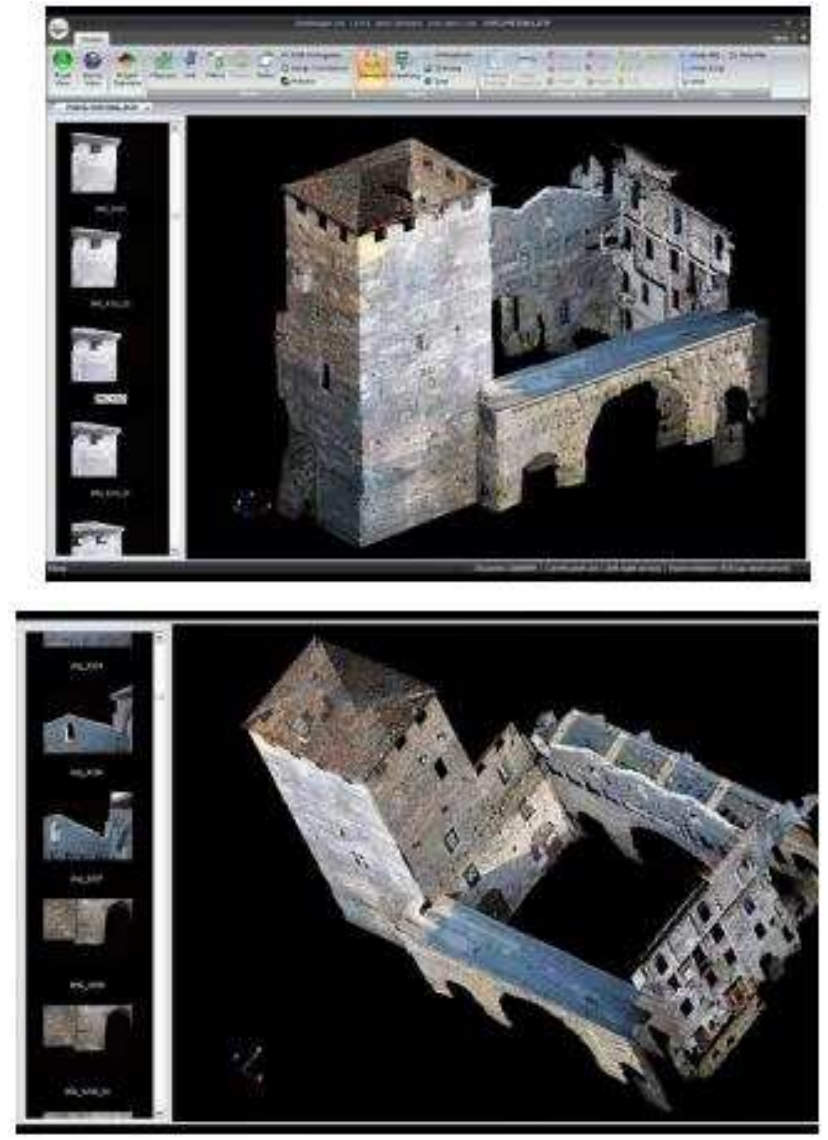

Figure 3: 3D point cloud models with RGB information

\section{THE INTEGRATION OF HETEROGENEOUS DATA}

\subsection{The integration and data management ARKIS}

As mentioned above, in order to monitor the monument over time, the priority objective of the whole operation is to reach a "critical use" of the acquired data, by optimizing the processes of integration and analysis in specific environments, providing thereby a valuable tool for decision support and the planning of the work of individual technicians. The data, therefore, whether geometric or descriptive of the condition, material, etc. have been structured in an information system designed to integrate complex, heterogeneous information related to various acquisitions at each stage of the cognitive approach to the manufacture (three-dimensional relief, visual analysis and / or instrumental). The system is represented by software called ARKIS (Architecture Recovery Knowledge Information System) developed in language AVENUE, environment in ArcView (ESRI), the innovative aspect is the transfer of specific functions of GIS (Geographical Information System), to the architectural scale. The system structure permits to directly import the geometric data (raster from ortophotos, CAD vector, etc.) obtained during the survey or acquired through scanning other documentation that may exist in archives [9]. On this geometric basis, restorers, or others involved in the project, can draw or study the different themes, specially configured to meet the requirements of the investigation (mapping of changes in degradation, stratigraphy, past restoration etc.). To these themes, developed in close collaboration with technician in charge, are associated alphanumeric information previously collected by appropriate analysis (instrumental, "visible", documentary, etc.); the system ARKIS allows, in fact, being a GIS, to interrelate, through a specially configured interface, the description given in the chart with the 3D surveyed area (Figure 4). 


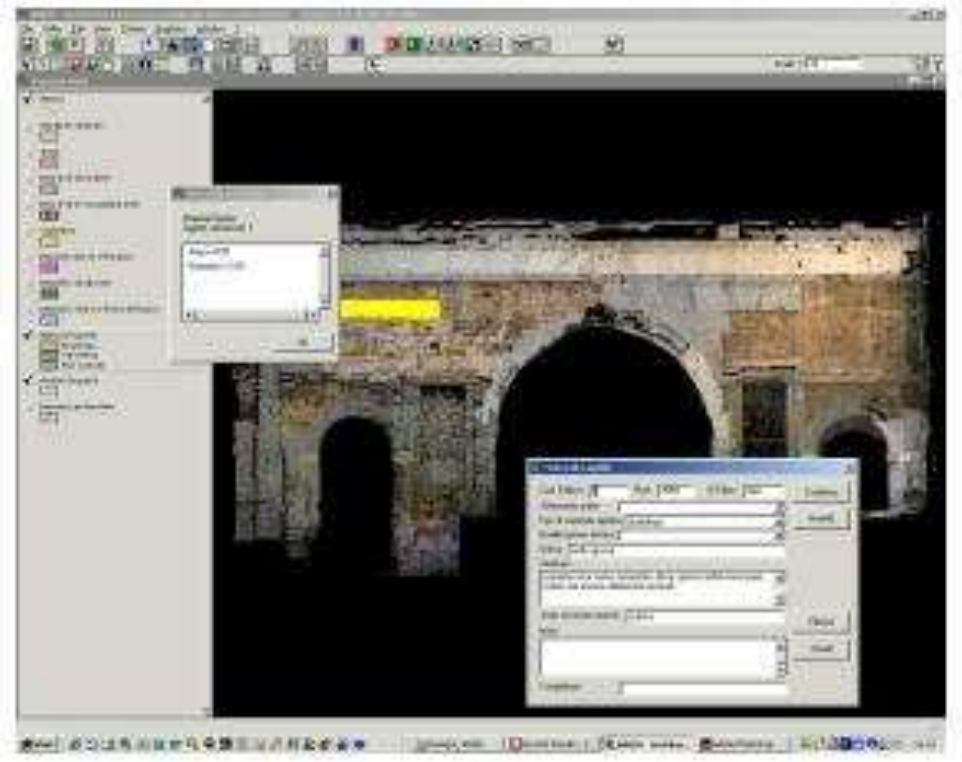

Figure 4: ARKIS - consultation phase data on the east side of the Praetorian door

The topics and related information is spatially and uniquely determined trough the topology tool, basis of GIS technology. The use of the ARKIS system has been part of the training on job project done in close collaboration with operators of the Administration involved, in order transfer the know-how which makes the Administration of Cultural Heritage of Aosta completely autonomous in the use of the system. The system ARKIS tool, once available on web, will allow restorers to access and view the data directly from the work site; the operators of the Superintendent will also record all data in time for laboratory analysis and restoration, with a view to its conservation budget and schedule.

\section{CONCLUSIONS}

The work as far as here presented remarks how "traditional" ways can still be pursued and enforced as valid applications to survey Cultural Heritage. Systems based on image capture and processing, for digitization and 3D model reconstruction can be widely applied to different scale archaeological artifacts, also allowing common users to quickly understand their configuration and peculiar characteristics [10]. Digital photogrammetry has given satisfactory results in terms of surveyed number of points and precision in the location of the acquired surfaces, taking advantage of UAV technology. Moreover digital quick photogrammetry - photo-scanner - achieving at the same time both the geometric and the color documentation (points clouds with RGB color information), photo-realistic 3D models could be easily outputted on as a high quality level as of those created from laser scanner's dataset trough a longer post-processing texturing work. Morphological details or components materials and colorimetric definitions so could be extensively exploited in further analysis by specialists from various technical fields. Finally is to underline the low cost of this technology which offers to peripheral museums or small Public Administration the opportunity to plan surveys and preservation of own artifacts otherwise not possible if more expensive technologies and methodologies, as laser scanner sensors, are involved, that question us on ethical responsibilities of the use of too expensive hardware in Cultural Heritage knowledge.

\section{REFERENCES}

[1] Promis, C., 1862. Le antichità di Aosta, Capo VII, § 1. Porta Pretoria nello stato presente, Stamperia Reale, Torino, 1862, 142-156.

[2] Drap, P., Sgrenzaroli, M., Canciani, M., Cannata, G., Seinturier, J., 2003. Laser Scanning and close range photogrammetry: Towards a single measuring tool dedicated to architecture and archaeology, in Proceeding ISPRS symposium.

[3] Salonia, P., Scolastico, S., Bellucci, V., 2006. Laser scanner, quick stereo-photogrammetric system, 3D modelling: new tools for the analysis and the documentation of cultural archaeological heritage, in Proceedings of 2nd international conference on remote sensing in archaeology, Rome. 
[4] Salonia, P., Bellucci, V., Scolastico, S., Marcolongo, M., Leti Messina, T., 2007. 3D survey technologies for reconstruction, analysis and diagnosis in the conservation process of cultural heritage, in Proceedings of Cipa 2007 XXI International Symposium. Anticipating the future of the cultural past, 1-6 October 2007, Athens, Greece.

[5] Salonia, P., Leti Messina, T., Marcolongo, A., Scolastico, S., 2009. Three focal photogrammetry application for multi-scale and multi-level Cultural Heritage survey, documentation and 3D reconstruction, in Proceedings of The 22nd CIPA Symposium 2009, Kyoto.

[6] Menci Software Homepage. http://www.menci.com/ .

[7] Salonia, P., Leti Messina, T., Marcolongo, A., Scolastico, S., 2009. Survey and 3D reconstruction of the St. Orso capitals in Aosta, through three-focal photogrammetry, in Proceedings of The 10th International Symposium on Virtual Reality, Archaeology and Cultural Heritage VAST 2009.

[8] The CENOBIUM Project's Homepage 2009. http://cenobium.isti.cnr.it/ index.php.

[9] Salonia, P., 2003. Strumenti informatici innovativi di ausilio alla conservazione del patrimonio storico architettonico: problemi di organizzazione, diffusione e gestione dati, in Rossi M., Salonia P., a cura di, , Comunicazione Multimediale per i Beni Culturali, Addison-Wesley, Milano 2003.

[10] Martinelli, M., 2006. Passato e futuro del 3D archeologico, dalle foto stereoscopiche al computer per l'architettura antica, Arkos, 16, pp. 18-23. 